\title{
EXIBINDO SEUS MÚSCULOS: A SINALIZAÇÃO EM MACHOS DE LIBÉLULAS INDICA SUA CONDIÇÃO CORPÓREA? Douglas Fernandes Maciel Costa ${ }^{1}$; Paulo Enrique Cardoso Peixoto ${ }^{2}$
}

1. Bolsista PIBIC/FAPESB, Graduando em Ciências Biológicas, Universidade Estadual de Feira de Santana, e-mail:

macieluefs@gmail.com

2. Orientador, Paulo Enrique Cardoso Peixoto, Departamento de Zoologia, Universidade Estadual de Feira de Santana, e-mail: pauloenrique@gmail.com \author{
sinalização.
}

PALAVRA-CHAVE: Seleção sexual; Dimorfismo sexual;

Dimorfismo sexual é a diferença física entre machos e fêmeas (Andersson 1994). A competição entre machos pelo acesso a fêmeas pode levar à evolução de atributos sexualmente dimórficos (dimorfismo sexual). Esses atributos presentes de forma mais exagerada nos machos supostamente sinalizam a qualidade fisiológica do indivíduo, seja para rivais em interações agonísticas ou para fêmeas na escolha de parceiros sexuais (Andersson 1994).

As brigas entre machos por acesso a fêmeas, que frequentemente ocorrem na forma de briga, podem ser muito custosas, pois consomem grande parte do orçamento temporal e energético dos indivíduos, além de poderem causar lesões (Arnott \& Elwood 2009). Logo, mecanismos que permitam que os indivíduos avaliem seus rivais e decidam se devem entrar em um confronto deveriam ser favorecidos (Enquist \& Leimar 1983). Em algumas espécies esses atributos indicam a condição nutricional do indivíduo (Zahavi 1975, Zuk 1996). Porém, em outas espécies os machos são selecionados por possuírem atributos que são mais atrativos para as fêmeas, mesmo que tais atributos não indiquem vantagens para elas, a não ser a manutenção da atratividade na prole (seleção desenfreada - Prokop et al. 2012).

Em libélulas a maioria do dimorfismo consiste em padrões de colorações mais conspícuas geralmente nas asas e no tórax dos machos (Córdoba-Aguilar, 2008). Em Erythrodiplax clitella o dimorfismo sexual consiste em manchas alares escuras e manchas brancas abdominais presentes apenas nos machos. Nesse estudo, usamos machos de E. clitella para avaliar a hipótese de que as manchas alares e abdominais indicam a condição nutricional dos machos. Nossa previsão é de que quanto maior a área da mancha alar e da mancha abdominal, maior a massa de gordura corpórea ou maior massa corpórea do individuo.

\section{Método}

Desenvolvemos este estudo em lagos na região de Feira de Santana $\left(12^{\circ} \mathrm{S}-38^{\circ}\right.$ O), Bahia, Brasil. De acordo com a classificação de Köppen, o clima da região e Aw (tropical). Caracterizado por temperatura média no mês mais frio superior a $18{ }^{\circ} \mathrm{C}$ e inverno mais chuvoso que o verão.

Coletamos machos da espécie E. clitella. Em seguida, fotografamos as manchas abdominais e alares usando uma maquina fotográfica digital, em seguida, medimos a área de cada mancha usando o programa Image $\mathrm{J}$ - versão 1.38. Para estimar a massa de gordura, secamos cada indivíduo em estufa a $50{ }^{\circ} \mathrm{C}$ por $24 \mathrm{~h}$. Em seguida, pesamos separadamente o tórax (sem pernas e sem asas) e o abdome de cada um. Posteriormente, colocamos o tórax e o abdome em um recipiente fechado com $10 \mathrm{ml}$ de clorofórmio por $48 \mathrm{~h}$ para extração de lipídeos. Em seguida, secamos os indivíduos na estufa a $50{ }^{\circ} \mathrm{C}$ por 48 h. Após esta etapa, pesamos mais uma vez cada indivíduo. Usamos a diferença do 
peso entre a primeira e a segunda pesagem como uma estimativa da quantidade de gordura. Em seguida usamos a primeira pesagem como estimativos da massa corpórea total (peso seco).

Para avaliar se as manchas alares ou abdominais estão associadas à quantidade de gordura, fizemos regressões lineares considerando a massa de gordura e a massa corpóreas como variáveis respostas e a área da mancha alar ou abdominal como variáveis explicativas.

\section{Resultados}

Não encontramos relação significativa entre a área da mancha alar $\left(13 \pm 2,5 \mathrm{~mm}^{2}\right)$ (média $\pm \mathrm{DP})$ e a quantidade de gordura corporal $\left(2,9 \pm 2,4 \mathrm{mg} ; \mathrm{F}_{(1,12)}=0,64 ; \mathrm{b}=-0,3 \pm\right.$ $0,31$ (estimativa $\pm E P) ; r^{2}=0,08 ; p=0,44 ;$ Fig. 1a). Também não encontramos relação entre a área da mancha alar e o peso seco $\left(26,7 \pm 3,1 \mathrm{mg} ; \mathrm{F}_{(1,12)}=0,43 ; \mathrm{b}=\mathrm{P}=0,53\right.$; Fig. 1b). Encontramos dois outliers em cada uma das análises anteriores. Porém, com a remoção destes pontos, houve quebra de pressupostos para realização de uma regressão linear múltipla, pois a variância ficou heterogênea. Para solucionar esse problema, decidimos realizar um teste de Spearman. Novamente, não encontramos relação entre área da mancha alar $\left(13 \pm 2,5 \mathrm{~mm}^{2}\right)$ e a massa de gordura corpórea $(2 \pm 0,9 \mathrm{mg} ; \mathrm{S}=397 ; \mathrm{n}$ $=13 ; \mathrm{P}=0,76)$. Também não encontramos relação entre a área da mancha alar e peso $\operatorname{seco}(27,7 \pm 1,5 \mathrm{mg} ; \mathrm{S}=528,2 ; \mathrm{n}=13 ; \mathrm{P}=0,12)$.

De forma similar ao observado para as manchas alares, não encontramos relação entre a área da manha abdominal $\left(25 \pm 4,9 \mathrm{~mm}^{2}\right)$ e a quantidade de gordura corpórea $\left(F_{(1,12)}=0,15 ; b=-0,16 \pm 0,8 ; r^{2}=0,25 ; P=0,69 ;\right.$ Fig. $\left.2 a\right)$. Também não encontramos relação entre a manha abdominal e o peso seco $\left(F_{(1,12)}=3,9 ; b=-0,16 \pm 0,8 ; r^{2}=0,25 ; P\right.$ $=0,07$; Fig. 2b). Para essas análises envolvendo a mancha abdominal, também encontramos dois outliers. Porém, novamente houve quebra de pressuposto para realizar a regressão linear sem eles. Ao realizar correlações de Spearman considerando os dados em os outliers, não encontramos relação entre a área da mancha abdominal $(25 \pm 5,2$ $\left.\mathrm{mm}^{2}\right)$ e a massa de gordura corporal $(2 \pm 0,9 \mathrm{mg} ; \mathrm{S}=350 ; \mathrm{n}=13 ; \mathrm{P}=0,9)$. Também não encontramos relação entre a área da mancha abdominal $\left(25 \pm 4 \mathrm{~mm}^{2}\right)$ e o peso seco $(27,5 \pm 1,5 \mathrm{mg} ; \mathrm{S}=399 ; \mathrm{n}=13 ; \mathrm{P}=0,75)$.

\section{Discussão}

Esses resultados indicam que as manchas não sinalizam a condição nutricional dos indivíduos. Talvez as manchas alares tenham evoluído por um processo de seleção desenfreada. Já as manchas abominais, por serem brancas, podem ter papel na termorregulação.

\section{Conclusão}

A ausência de relação entre a área das manchas alares e abdominais com a massa de gordura ou com o peso seco indicam que essas manchas não evoluíram por sinalizar a condição nutricional dos indivíduos. A mancha alar pode ter evoluído pelo mecanismo de seleção desenfreada. Já a mancha abdominal pode ter uma importância na termorregulação desses indivíduos. 
A

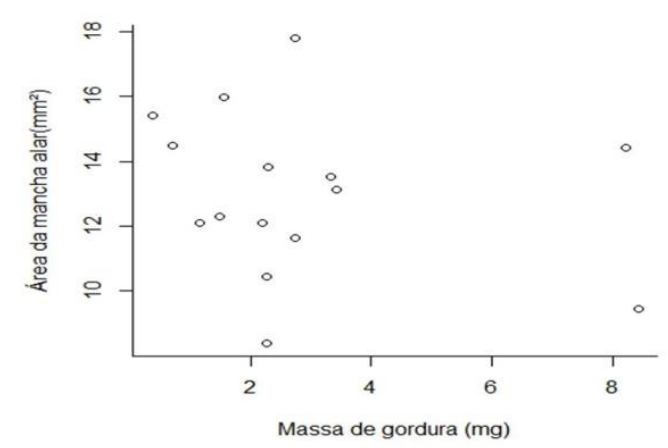

B

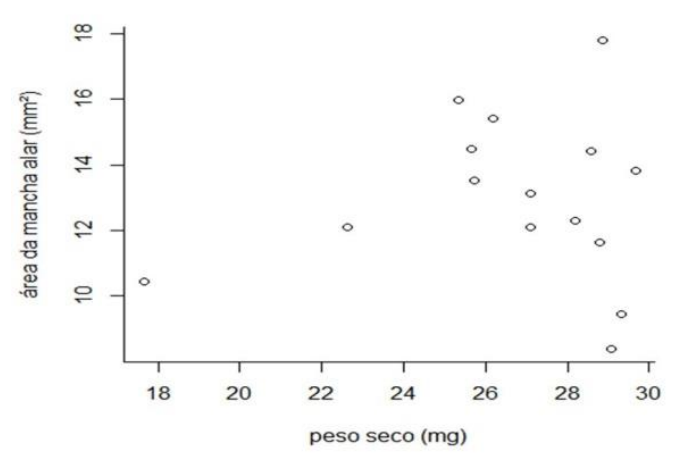

Fig 1: relação entre a área da mancha alar e a massa de gordura (A) e entre a área da mancha alar e o peso seco (B) de machos de Erythrodiplax clitella coletados em lagos da cidade de Feira d Santana, Bahia, Brasil.

A

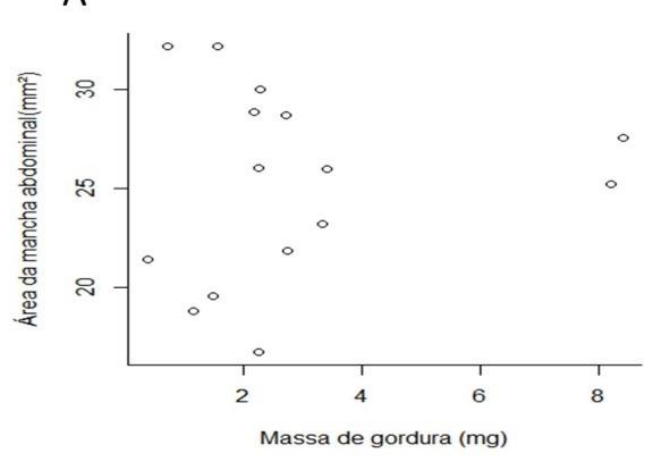

B

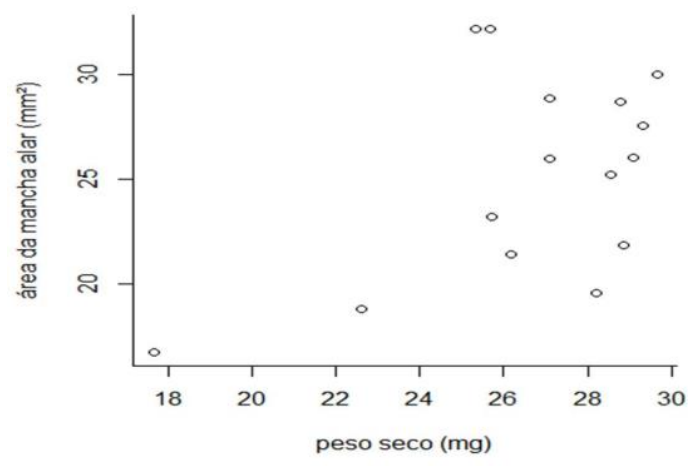

Fig 2: relação entre a área da mancha abdominal e a massa de gordura (A) e entre a área da mancha abdominal e o peso seco (B) de machos de Erythrodiplax clitella coletados em lagos da cidade de Feira d Santana, Bahia, Brasil. 


\section{Referência}

ANDERSSON, M. 1994. Sexual selection. Princeton: Princeton University Press.

Arnott, G. \& Elwood, R. W. 2009. Assessment of fighting ability in animal contests. Animal Behaviour, 77, 991-1004.

Córdoba-Aguilar, A. 2008. Dragonflies and damselflies: model organisms for ecological and evolutionary studies. Oxford: Oxford University Press.

Enquist, M. \& Leimar, O. 1983. Evolution of fighting behavior decision rules and assessment of relative strength. Journal of Theoretical Biology, 102, 387-410.

Prokop, Z. M., Michalczyk, L., Drobniak, S. M., Herdegen, M. \& Radwan, J. 2012. Meta-analysis suggests choosy females get sexy sons more than 'good genes'. Evolution, 66, 2665-2673.

Zahavi, A. 1975. Mate selection - a selection for a handicap. Journal of Theoretical Biology, 53, 205-214.

Zuk, M, 1996. Disease, endocrine-immune interactions, and sexual selection. Ecology, 4, 1037-1042. 